\title{
Olvido, rechazo y marginación en dos obras del teatro histórico mexicano: Felipe Ángeles de Elena Garro y El día más violento de Bárbara Colio.
}

\section{Oblivion, rejection and marginalization in two plays of the mexican historical theater: Felipe Ángeles by Elena Garro and El día más violento by Bárbara Colio.}

DOI: 10.32870/sincronia.axxv.n80.16b21

\author{
Ricardo Torres Miguel \\ Universidad Autónoma Metropolitana- Iztapalapa (MÉXICO) \\ CE: ricksabato@gmail.com / ORCID: 0000-0001-9090-1416
}

Esta obra está bajo una Licencia Creative Commons Atribución-NoComercial 4.0 Internacional

Recibido: 31/03/2021

Revisado: $14 / 05 / 2021$

Aprobado: 14/06/2021

\section{RESUMEN}

Felipe Ángeles de Elena Garro y El día más violento de Bárbara Colio son dos obras que abordan personajes un tanto oscuros en la historia de la Revolución mexicana. Ambas piezas versan sobre personajes que no han figurado en la cosmovisión del aparato nacionalista revolucionario, quizá por ser mujeres, como en el caso de la pieza de Colio, o por atreverse a poner en tela de juicio los triunfos de dicha gesta, como la pieza sobre el mítico general hidalguense. Aunque haya una separación de más de 40 años, la escritura de Garro y la de Colio teje puentes, tanto en la visión femenina de la dramaturgia mexicana, como en la de los héroes históricos y que, a pesar de ser personajes rechazados, olvidados o marginados, el teatro poco a poco les ha ofrecido un poco de justicia poética.

Palabras claves: Revolución mexicana. Memoria histórica. Carmen Serdán. Escritura femenina. 


\begin{abstract}
Felipe Ángeles by Elena Garro and Bárbara Colio's El día más violento are two works that address somewhat dark characters in the history of the Mexican Revolution. Both pieces are about characters that have not been included in the worldview of the revolutionary nationalist apparatus, perhaps because they are women, as in the case of Colio's piece, or for daring to question the triumphs of that gesture, such as the piece on the hidalguense mythical General. Although there is a separation of more than 40 years, the writing of Garro and that of Colio weaves bridges, both in the feminine vision of mexican dramaturgy, and that of the historical heroes and who, despite being rejected, forgotten or marginalized characters, the theater has gradually offered them a little poetic justice.
\end{abstract}

Keywords: Mexican Revolution. historical memory. Carmen Serdán. Female writing.

Compañeras: la catástrofe está en marcha, airados los ojos, el rojo pelo del aire, nerviosas las manos prontas a llamar a las puertas de la patria. Esperémosla con serenidad. Ella, aunque trae en su seno la muerte, es anuncio de vida, es heraldo de esperanza. Destruirá y creará al mismo tiempo; derribará y construirá. Sus puños son los puños formidables del pueblo en rebelión. No trae rosas ni caricias: trae una (sic) hacha y una tea.

Ricardo Flores Magón (2001). “A la mujer (De Regeneración, septiembre 24 de 1910)".

Elena Garro (1916-1998) fue una de las novelistas más destacadas que ha tenido México, su producción narrativa resalta sobre sus otros intereses, pero es menester decir que incursionó en otras artes como la danza, la poesía (en su mayoría inédita), la coreografía, el periodismo y, sobre todo, el teatro. La reciente publicación de Teatro completo, editado por el Fondo de Cultura Económica, permite ver la gran capacidad creativa que poseía Garro y, además, comprobueba su conocimeinto de diversos temas, entre ellos el teatro de corte histórico con Felipe Ángeles, que se publicó por primera vez en la revista Coátl. La obra sobre el general Ángeles se movió entre las 
sombras por mucho tiempo, hasta que fue montada en 1978 por la UNAM, luego le siguió la edición de Patricia Rosas Lopátegui, Teatro de Elena Garro, en 1999. En ese mismo año, dentro del XXVII Festival Cervantino se reestrenó Felipe Ángeles en el Teatro Principal en Guanajuato, bajo la dirección de Luis de Tavira. Esta producción también se presentó en la Ciudad de México en el teatro Julio Castillo (Seydel, 2006, p. 106). En 2019, se volvió a montar en el teatro Juan Moisés Calleja del IMSS con la dirección de Rodolfo Guerrero y por una corta temporada (Rivera).

Bárbara Colio (1969) es una de las voces teatrales más importantes de los últimos años, además de su labor dramatúrgica, se dedica a la docencia y a la crítica teatral. Posee una carrera sólida con más de 20 obras publicadas, las cuales han sido llevadas a escena en México, Estados Unidos, Europa y Sudamérica. Ha recibido diversos premios, entre los que destacan el Premio Internacional María Teresa León para Autoras Dramáticas 2004 (España) por su obra Pequeñas certezas, el Premio Nacional de Dramaturgia Víctor Hugo Rascón Banda 2009 por Usted está aquí y el Premio Bellas Artes, Baja California de Dramaturgia 2009 por su obra Cuerdas. En el año 2017, por su trayectoria y constancia en las artes escénicas, obtuvo el premio Juan Ruiz de Alarcón. En 2011, en conjunto con la Compañía Nacional de Teatro de México y la editorial Jus se publica El día más violento (2011), obra en la que Colio toca el tema de las mujeres en la historia con el personaje de Carmen Serdán, la célebre poblana que fue olvidada por la historia y la que tuvo que esperar demasiado tiempo en la oscuridad para que se le reconociera su papel en la revuelta de 1910.

De tal suerte que Felipe Ángeles de Elena Garro (2016) y El día más violento de Bárbara Colio son dos obras que abordan personajes un tanto oscuros en la historia de la Revolución mexicana. Ambas piezas versan sobre personajes que no han figurado en la cosmovisión del aparato nacionalista revolucionario, quizá por ser mujeres, como en el caso de la pieza de Colio, o por atreverse a poner en tela de juicio los triunfos de dicha gesta, como la pieza sobre el mítico general hidalguense.

En este texto se analizará cómo, aunque haya una separación de más de 40 años, la escritura de Garro y la de Colio teje puentes, tanto en la visión femenina de la dramaturgia mexicana, como 
en la de los héroes históricos y que, a pesar de ser personajes rechazados, olvidados o marginados, el teatro poco a poco les ha ofrecido un poco de justicia poética.

En la obra de Elena Garro nos adentramos en uno de los episodios más sombríos de la Revolución mexicana, donde el general Felipe Ángeles es asesinado por sus correligionarios. Aquí la escritora nos cuenta la historia no dicha, la de las traiciones, los pactos secretos, las corruptelas y sobre todo la continuación de los tiranos que sobrevivieron a la revuelta y lo peor de todo, donde se vuelven los vencedores. Su historia es, de igual forma, la de los vencidos, la de los marginados, de los que perdieron todo en la lucha, incluso su propia vida. La versión de la dramaturga nos adentra en los ideales más profundos del general revolucionario, nos muestra sus lágrimas, sus miedos y sus inseguridades, tal como si se tratara del general revolucionario en sus últimas horas.

En cuanto a Carmen Serdán, Bárbara Colio nos presenta un destino posible de la hermana mayor de Aquiles, después de los eventos de la guerra. La autora se hace varias preguntas como ¿qué habría pasado después del asesinato de sus hermanos y cuál fue el verdadero destino de Carmen? En una suerte de realismo mágico, la dramaturga mexicalense nos expone cómo hubiera seguido la revolucionaria con su vida, con sus culpas y sus anhelos rotos. Se nos ejemplifica, notablemente, cómo la Revolución no hizo justicia a todos, puesto que hizo héroes a algunos y a otros simplemente los olvidó, ya sea por ser mujeres o, como dice la escritora, por cometer el pecado de no morir jóvenes. El día más violento, como dice Colio, no es histórica, sin embargo, representa perfectamente la vida de una mujer que la historia tuvo en la penumbra por bastante tiempo, y que el teatro ha podido hoy darnos una luz de esperanza para conocer un poco más de la primera guerrera de la Revolución.

El ejercicio de comparar dos piezas, con más diferencias que similitudes, radica en mostrar cómo el teatro ha sido capaz de reflejar la historia y los problemas sociales, aun cuando haya una brecha de más de 40 años entre estas obras. El objetivo de este trabajo será demostrar que el teatro de Elena Garro y el de Bárbara Colio parte de los mismos presupuestos sociales, es decir, los que persiguen combatir la invisibilidad y la injusticia en que tanto tiempo estuvieron Serdán y Ángeles. La teatralidad de ambas dramaturgas, aunque sea muy diferente, evoca, inspira y recupera 
el pasado de estos personajes ilustres, los acerca a nosotros como espectadores y construye una visión del mundo y al menos en escena, se resemantiza la historia y se vuelve a contar o, mejor dicho, se aprende a contar. De esta manera, tenemos dos obras en donde se trata de buscar reconocimiento para los personajes, ya sea a través de los datos históricos o por medio de la reconstrucción ficticia de sus vidas. Ambas piezas presentan estructuras bastante dispares, por lo que comenzaremos por explicar la obra de la escritora poblana.

\section{Felipe Ángeles. Elena Garro}

Está dividida en tres actos y temporalmente se fija en 24 horas, lo que nos plantea un esquema aristotélico tradicional. Se trata de una tragedia clásica en su más pura acepción, el camino del héroe hacia su destino final es la trama principal de la obra. Por otro lado, la pieza no hace uso de recursos vanguardistas como el absurdo o el surrealismo, presentes en muchas de las obras de Garro. Aquí, el enfoque es enteramente realista y se dirige a contar la agonía del general revolucionario. La historia nace de una profunda investigación hecha por Elena Garro, en la que se involucró en la labor histórica de desentrañar los misterios provenientes de los archivos de la Secretaría de la Defensa Nacional (SEDENA). Como resultado de esto, la obra es tremendamente fidedigna, Felipe Ángeles regresa de su exilio, es apresado y empieza su calvario durante prácticamente todo un día. El Teatro de los Héroes de Chihuahua es el lugar donde se dan los hechos, ahí servirá como cárcel y como el sitio de la sentencia. Por supuesto, el lugar indica una mención metateatral, pues como dice Jesús G. Maestro (2004):

El metateatro potencia formalmente la percepción del concepto barroco del theatrum mundi. Subraya de este modo la posible relación existente entre mundo y teatro, y cumple con una efectiva intención reveladora de desmitificación, de denuncia social y política en algunos casos, y de expresión, sencillamente, en otros casos, de determinadas concepciones dramáticas y poéticas (p. 3, 4). 
En una especie de destino trágico, el teatro es el último lugar donde Ángeles habrá de defender su honor y su vida:

Escobar (señalando el teatro): Ahora me explico por qué vamos a juzgarlo en un teatro.

Diéguez (serio): ¿Qué quiere usted decir, general?

Escobar: ¡Nada! Que a mí me cuesta trabajo aprenderme los papeles de memoria...

Gómez Luna: No hay que desesperar. Haremos que de esta farsa surja la verdad y el gobierno tendrá que retroceder (Garro, 2016, p. 187, 191).

El metateatro tiene la función de evocar una realidad suprema, de mostrar al espectador que lo que ve tiene un trasfondo ulterior, a veces mágico, y otras suele ser completamente realista y desafiante de lo que se ve a primera instancia:

Al confrontar, en una especie de juego de espejos, a los espectadores de su obra Felipe Ángeles con la forma de actuar del público durante el juicio, Elena Garro los invita a reflexionar sobre su propio compromiso político y sobre el interrogante de si ellos intervendrían activamente para impedir que se cometa una injusticia contra un ciudadano o si preferirían resignarse a silbar, aplaudir o gritar, así como conformarse con su papel de espectadores de la represión en contra de un disidente político, que se ha convertido en la víctima de la maquinaria del poder (Seydel, 2006, p. 111).

Y, según Galván (1987), es aquí donde se nos sitúa como héroe trágico al general revolucionario: “Ángeles se parece a Prometeo en el uso de la razón y no la fuerza, en la insatisfacción de ver que la razón le asiste, pero es impotente para sostenerla y en su generosidad por el deseo de beneficiar a la humanidad" (p. 30). Hay un extracto del juicio del general Ángeles que reproduce Osorio (2008), que se podría parecer mucho a lo que decía Galván hace unas cuantas líneas: "-Yo sé que voy a morir, pero mi muerte hará más bien que mis acciones durante mi vida, porque la sangre de los mártires fecunda el suelo donde brotan los ideales" (p. 180). Es de esta faceta heroica del revolucionario de donde Garro construye su obra. La versión apasionada e idealista del general es lo que hace que la escritora posicione su visión del mundo sobre esta tragedia. Además, la dramaturga 
elabora al personaje para que haga uso de la elocutio para mostrar varios exempla que busquen persuadir y convencer a sus oponentes, no de su inocencia, sino del valor de la Revolución.

Es claro el uso de la retórica clásica en esta obra, por ello es notable un claro lirismo en las palabras del general:

Su defensa es enérgica y viril, pero revela al mismo tiempo una personalidad un tanto andrógina, sensata, razonable y mansa, que no ofrece resistencia cuando lo aprehenden, que solloza al pensar que la posteridad lo juzgará como tonto. La autora lo contrasta con el machismo de Obregón: el que los fusila a todos. (Galván, 1987, p. 30).

Es aquí donde aparece otro de los rasgos del héroe trágico: el sacrificio.

Lo único que defiendo en estos momentos son mis acciones. Señores jurados: cuando ustedes hayan votado que se me aplique la pena de muerte y yo haya desaparecido, mi único anhelo es que no se diga que fui un hombre malo. (Osorio, 2008, p. 191).

Ángeles se percibe derrotado y sabe, que pese a todo su esfuerzo y el de los abogados y las señoras, será fusilado porque el "primer jefe" así ya lo ha decidido. "Señora Revilla: Pedimos un juicio legal. Tiempo, defensores, o bien la suspensión del juicio, ya que éste ha sido declarado ilegal por la justicia de la Unión" (Garro, 2016, p. 184). Por ello, de alguna manera, disfruta su momento y saborea su anticipado triunfo, pues la victoria del honor para el héroe ningún tirano podrá quitársela. "Felipe Ángeles, a los ojos de Garro, sobrevive al fusilamiento gracias a la palabra dicha. Hay un anhelo de eternidad en su invocación, a sabiendas de que sólo existe lo que tiene nombre" (Olguín, 2011, p. 191).

Por supuesto, este lirismo que se muestra en los diálogos del condenado no es gratuito, en el discurso del general Felipe Ángeles, que Garro reproduce en su obra, se utilizan diversas funciones estilísticas y semánticas de la primera persona del singular, como es el caso de mostrar el deseo de resistir y ser mártir ante la vorágine que se avecina:

Yo redacté el telegrama que cruzó el rostro de Carranza como un fuetazo. Por mí fuimos a Zacatecas y vencimos finalmente a Huerta. Yo soy el culpable de que, desoyendo los 
despóticos mandatos de Carranza, hayamos ido a dar el último golpe de muerte a los huertistas. Yo soy el culpable de haberle dicho a Carranza su miseria moral, su envidia, su falta de patriotismo, su ambición, su despotismo (Garro, 2016, p. 177). ${ }^{1}$

Este uso repetido del pronombre personal demuestra el enorme sacrificio que el general hace, pero esto también significa ponderar el papel protagónico de Ángeles ante la injusticia que se estaba cometiendo hacia él y la causa que perseguía.

La mayor parte de la crítica en torno a Felipe Ángeles ha visto a la obra como una especie de rito ancestral, en donde el héroe azteca, victorioso de las guerras floridas, regresa para cumplir su ciclo, su destino final: el sacrificio. Este leitmotiv de la crítica es pertinente porque, efectivamente, el personaje pareciera seguir un círculo hacia la tragedia, la asume y enarbola orgulloso su marca, su estigma como víctima de un destino funesto. En la obra, el general se mantiene estoico y por momento bastante negativo (según la caracterización de Garro), sabedor de que no llegará el perdón y que si éste llega será tarde.

Ángeles: La muerte de un hombre, abogado, es algo determinado desde antes de su nacimiento.

López Hermosa: No acepto sus razones para morir, general.

Ángeles: Los destinos secretos de la muerte nadie los conoce. Además, la muerte es el único privilegio privado que acepto... cada uno muere de su propia muerte (Ángeles se ríe.) (Garro, 2016, p. 194).

Esta carga emocional, que se da a lo largo de la obra, es lo que potencia el discurso del personaje. Para Garro, el poder de las palabras del general resuena más fuerte que las balas, que al final habrán de terminar con su vida.

Lo que hace Elena Garro en esta obra es continuar la lección que el héroe trajo a su regreso, de cambiar la espada por la palabra y por las ideas y proponer la razón, la inteligencia y la civilización en la sociedad. La autora entonces, con base en un hecho

\footnotetext{
${ }^{1}$ Las cursivas son mías.
} 
histórico ha escogido a un personaje que había sido olvidado y lo ha hecho renacer en base a sus características humanas, éticas e intelectuales y lo presenta como personaje al mismo tiempo que viril, un tanto andrógino, muy diferente al personaje esterotípico (sic) revolucionario (Galván, 1987, p. 34).

Esta base humanista es la que sostiene al personaje de Garro, sin ser religioso, Ángeles intenta persuadir a su audiencia a través de la fraternidad y el amor a los seres humanos. Así lo expone también Osorio: "Terminó, finalmente, como San Francisco de Asís, por declarar su amor a los animales y a todas las cosas: a los paisajes de su tierra, al sistema planetario, a la nebulosa que se tiende por el inmenso océano, a las estrellas, a todo... Y todo esto, expresado en medio de un impresionante silencio" (p. 191). Esto demuestra que, en un esfuerzo vano de hacer empatía con sus verdugos, el general, en la vida real, intentó alargar lo más posible su fin. En la obra de Garro, Ángeles está cansado, tiene las esperanzas de parte de la señora Revilla y sus abogados, pero al mismo tiempo abraza la idea de ser mártir, de que su sacrificio valga la pena:

Ángeles: Nadie se escapa, Bautista. La huida es una ilusión y en este caso no creo que valga la pena el riesgo.

Bautista: No hay riesgo, general. Todos los generales del Consejo de Guerra se fueron hoy mismo de Chihuahua. Sólo quedó Escobar... no sé para qué se quedaría ése, pero es lo de menos. Yo soy el encargado de fusilarlo. Mi cabeza depende de la suya. ¿Ve, general? Sin proponérnoslo, nos columpiamos del mismo mecate por encima de la muerte. iY quiero corrérmela con usted!

Ángeles: Usted es el único que se la corre, Bautista, mi vida ya está perdida (Garro, 2016, p. 226).

Bautista le ofrece la salida fácil, la que cualquiera hubiese tomado con tal de salvaguardar la vida, sin embargo, Ángeles prefiere la muerte anticipada, la que le otorga los ideales del ejército, la que le asegure que su honor permanecerá intacto y la que le dé, finalmente, la victoria sobre el déspota (Seydel, 2010, p. 85). 
Esta visión de buenos y malos, héroes y antihéroes es la que le interesa proponer a Elena Garro. La visión maniqueista es tal, que la dramaturga omite uno de los puntos centrales del juicio de Felipe Ángeles, es decir, su vínculo con Francisco Villa.

Las preguntas del agente del Ministerio Público electrizaron al público porque iban al meollo del asunto. Víctores Prieto deseaba que Ángeles condenara a Villa y negara la legitimidad de su lucha armada. Ángeles comprendió de inmediato la importancia de su respuesta y, necesitado de un poco de tiempo para meditarla, trató de eludirla (Osorio, 2008, p. 181).

La representación de Ángeles, por parte de Garro, prefiere fincarse en el carácter ideológico del personaje más que en el histórico, pues sobresale por todo lo alto las virtudes humanas y heroicas del general a costa de todo, incluso de sus propios intereses sentimentales, como sus hijos y su esposa. La obra busca mostrar la hipocresía de los políticos y la ambición del poder, contrastándolos con el amor a la patria y a los ideales de Felipe Ángeles.

Proveniente de este aspecto idealista y sonoro de las virtudes humanas del revolucionario, la crítica especializada no ha prestado suficiente atención al personaje de la señora Revilla y otras mujeres que luchan por la verdad y por salvar al general.

En un ambiente postrevolucionario en que los destinos de la sociedad pertenecen al ámbito masculino, se filtra la presencia femenina de la autora con un personaje que es su alter ego en la obra, la señora Revilla, y otras dos mujeres que promueven la defensa legal del héroe porque estos personajes tienen un concepto más claro de la justicia que los revolucionarios (Galván, 1987, p. 35).

La visión de la mujer mexicana entregada a los ideales de una causa justa y la desmitificación del clásico machismo patriarcal de la literatura de la Revolución es tan sólo uno de los altos valores en la obra de Garro. "De cualquier modo, la contribución y el relato histórico que realiza Elena Garro se inscribe, como en el caso de Nellie Campobello, en ese coto de la narración, ya sea histórica, ya sea ficcional, sobre la Revolución Mexicana, considerado masculino en exclusividad" 
(Prado, 2006, p. 99). Esta visión femenina es, asimismo, uno de los atributos que la crítica en torno a Felipe Ángeles ha pasado de largo. Así lo vemos casi al final de la obra, cuando se da el diálogo entre la señora Revilla y el general:

Ángeles: [...] Me cuesta trabajo no llorar sobre mí mismo. No llorar sobre Clara, mi mujer, sobre mis hijos... Es mejor que no los hayan dejado cruzar la frontera. En su presencia me hubiera sido imposible morir.

Señora Revilla. Llore, general... (Garro, 2016, p. 238).

En la escena, el general finalmente se quiebra emocionalmente y nos muestra su lado más humano, en el que se separa del militar y ofrece al hombre abatido por la sinrazón de un juicio amañado e injusto. La presencia de la señora Revilla es, como dice Galván, el alter ego de Garro, quien consuela y da el último confort al revolucionario. Esta última parte es importante, porque como dice Gloria Prado, la mirada de mujer que la dramaturga imprime a eventos de índole sumamente polémicos, es una de las características poco analizadas del teatro histórico, que como se verá más adelante, la emparentan con otras escritoras que han puesto su mirada sobre este tipo de temas.

Elena Garro no vivió la Revolución mexicana, nació en 1916 y tenía apenas cinco años cuando se puede considerar que concluyó, pero sus indagaciones en los archivos históricos, los relatos familiares de quienes sí tomaron parte en la contienda y el procesamiento que hizo de ellos, aunado a su capacidad configuradora de personajes, ambientes, tiempos y espacios, la conducen a generar estos "reportajes biográficos" en los que refigura y les confiere nueva vida, desde una mirada propia, de mujer, una mujer muy especial, que expresa sus convicciones, sus preferencias e inscripciones, cincuenta años después del inicio de los acontecimientos históricos (Prado, 2006, p. 99, 100).

La representación del juicio de Felipe Ángeles hace justicia a su manera, al contarnos su historia, pues él es uno de tantos personajes poco difundidos por el aparato institucional oficial hasta hace pocos años. Hoy, a más de cincuenta años de haberse gestado esta magnífica obra, es encomiable darnos cuenta de toda la amplia serie de cualidades que todavía guarda esta pieza. 
Actualmente, con los años y los nuevos enfoques históricos, el personaje de Felipe Ángeles ha gozado de cierta popularidad y ha dejado, por el momento, su ambigüedad como individuo "fastidioso" para ciertos sectores en el poder gubernamental. Sin embargo, la obra de Garro se adelantó a posiciones ideológicas en donde les conviniera el rescate histórico del general Ángeles, y presentó una pieza atrevida y desafiante para los regímenes de su tiempo:

Tanto Garro como Ibargüengoitia, ambos discípulos de Rodolfo Usigli, fueron escritores incómodos, ya que manifestaron sus opiniones políticas sin reparo y en su aguda crítica de los generales que salieron victoriosos de la Revolución, abandonaron el discurso solemne y mostraron todos los mecanismos siniestros que caracterizaron a los acomodos y reacomodos de los políticos y militares vencedores (Seydel, 2006, p. 107).

Como se ha visto, la historia oficial suele cometer omisiones, olvidos o incluso rechazo para mencionar a algunos personajes incómodos para el poder. El caso de Felipe Ángeles poco a poco ha ido resonando más, y quizá, ya no sea ese individuo desconocido de la Revolución mexicana y por el contrario, pueda convertirse en un personaje de cierta popularidad.

\section{El día más violento. Bárbara Colio}

Algo similar ha pasado con Carmen, la mayor de los hermanos Serdán (aunque sin la fama actual de Ángeles), quien junto a Aquiles dio inicio a la gesta revolucionaria, por allá del 18 de noviembre de 1910. Al igual que al general hidalguense, a la valiente revolucionaria se le ha visto bajo dos ópticas, primero como copartícipe de los eventos de Santa Clara, número 4 y luego como una desconocida que:

[...] al sobrevivir por 38 años más, quedó sola, al frente de una familia de mujeres viudas y niños huérfanos, atestiguando la ingratitud de un movimiento social al que le entregó su vida y que no volvió a acordarse de ella. No fue algo que ellos decidieran. Así lo decidió la Revolución (Colio, 2011, p. 16). 
Sin embargo, como en el caso de la otra obra de este trabajo, hoy la ficción dramática puede brindarnos un poco de luz en la oscuridad. El día más violento es una obra muy reciente de la joven dramaturga Bárbara Colio en donde, como ya se dijo, se intenta reconstruir la memoria histórica de una mujer hasta hoy poco estudiada.

Se trata de una historia ficticia donde vemos a la protagonista, Carmen Serdán, en sus diferentes etapas de su vida y muerte. La obra hace hincapié en mostrarnos la reconstrucción de la vida de Serdán, después de los fatales eventos del 18 de noviembre de 1910, en donde ella perdió a prácticamente a toda su familia, entre ellos al célebre Aquiles. Por lo tanto, vemos al personaje transitar entre el pasado, el presente y el futuro. Con esto, la pieza aporta datos sobre la misteriosa vida de Carmen, como, por ejemplo, la famosa entrevista con Carranza y la petición de él para que ella intercediera con Zapata para limar "asperezas". Asimismo, observamos su dedicación en los hospitales cuando ella servía como enfermera, para finalmente conocer a la heroína vieja. Aquí, la obra se concentra en la imaginación para plantearnos una protagonista cansada y recelosa de los alcances y triunfos de la Revolución.

La obra consta de un solo acto y diez escenas. Abarca una temporalidad extensa entre los años de 1910, 1915, 1948 y la actualidad. El espacio también es difuso, pues se irá superponiendo, como si lo que viéramos fuera un sueño. A diferencia de Felipe Ángeles, esta pieza no emplea el planteamiento aristotélico, sino más bien utiliza un tiempo y espacios anacrónicos en donde los eventos pasan por diferentes regresiones o incluso por algunas anticipaciones. Por lo que podemos experimentar ciertas analepsis o prolepsis, según sea el caso. Se trata de un planteamiento surrealista, en donde los personajes transitan entre varios espacios superpuestos, como si fueran andamios, y en donde su vida deambula por espacios imaginarios, algunos son representados mediante el recuerdo, el deseo o la muerte.

Sin embargo, este tipo de teatralidad no vuelve a la obra confusa, sino que provoca que el espectador o lector se interese todavía más por lo que pasa con Carmen Serdán. Por ejemplo, en la escena cero, donde vemos a una Carmen vieja rompiendo un sobre, luego inmediatamente después, vemos a una Carmen muerta, quien será como una especie de guía que nos lleve de la 
mano a conocer la vida de la protagonista. Asimismo, esta pieza no tiene tantos personajes como la de Garro, de hecho, podría decirse que las tres mujeres que identificamos como Carmen, junto a Aquiles, son los más importantes. Un factor para comprender el sentido de esta historia es la idea de introducir tres perfiles con las diferentes etapas de la vida de Carmen, lo que dará la apariencia de una perdurabilidad; en cambio a Aquiles lo vemos siempre joven, como si el tiempo se hubiera detenido y la historia lo hubiera vuelto eterno.

Como ya se apuntó, la obra utiliza analepsis y prolepsis, por medio de las cuales vemos al personaje principal en diferentes circunstancias, incluso hablándonos desde la muerte, en el futuro. Luego saltamos a un cuadro del pasado, en el que está una Carmen vieja y luego una joven; con ello, obtenemos información de antes de los sucesos del 18 de noviembre y más adelante conocemos la amargura y la desazón del olvido, propios del tiempo presente.

Arquitecto: ¿Es... algún pariente de Aquiles Serdán?

Carmen Vieja: Su hermana mayor.

Arquitecto: Pero si toda esa familia... ¿ ¿usted qué no había...?

Carmen Vieja: ¿Muerto? Sí. Varios libros de secundaria dicen eso. Y de lo que muero es de risa. No se preocupe. Está bien que algunos crean que ya me morí. A veces yo también lo creo (Colio, 2011, p. 32).

Esta cita nos demuestra uno de los principales argumentos de este trabajo, ¿son las circunstancias de la guerra, el aparato nacionalista y patriarcal o la Historia las que olvidan? Pudieran ser ciertas todas estas premisas, pero los datos recabados nos indican, que nos encontramos con una idea de historia selectiva, que hace héroes a algunos y a otros, simplemente los condena a la marginación. De esto se ha investigado últimamente, tal es el caso de María Teresa Martínez Ortiz (2010), quien plantea:

El mito de la soldadera popular, como "La Adelita" o "La Valentina," aspira a contener la experiencia revolucionaria femenina colectiva, sin considerar nociones esenciales como lo son raza y/o clase social. Si bien hay un sinnúmero de caudillos como Pancho Villa, Emiliano 
Zapata, etc., la participación de la mujer ha permanecido invisible debido al arquetipo supresor de la soldadera (p. 45).

Aunque esto es cierto, en el periódico Regeneración del 24 de septiembre de 1910, es decir, a poco menos de dos meses del evento en Puebla, se hacía un llamado a la mujer a tomar las armas y acudir a la revuelta:

Compañeras: éste es el cuadro espantoso que ofrecen las modernas sociedades. Por este cuadro veis que hombres y mujeres sufren por igual la tiranía de un ambiente político y social que está en completo desacuerdo con los progresos de la civilización y las conquistas de la filosofía. En los momentos de angustia, dejad de elevar vuestros bellos ojos al cielo; ahí están aquellos que más han contribuido a hacer de vosotras las eternas esclavas. El remedio está aquí, en la Tierra, y es la rebelión (Flores, 2001, p. 34).

Por supuesto, esto no niega la nota anterior, de hecho, lo confirma, puesto que muy al inicio de la gesta había la preocupación de integrar a las mujeres al movimiento, no sólo como compañeras del hombre, sino como activos dentro de la lucha. De esto nos refiere Martínez, pues en su opinión:

Simbólicamente, Carmen Serdán debe ser considerada la primera guerrera de la Revolución mexicana. En Puebla, junto con sus hermanos Aquiles y Máximo, Carmen abrazó las armas para luchar por la causa revolucionaria por convicción propia (2010, p. 48).

Esta es una las críticas principales que proyecta el texto de Colio, pues se comprueba cómo los vencedores de la Revolución no retomaron a los primeros impulsores de la revuelta, como el caso de Carmen, sino que los dejaron en el olvido. Además, aquí estriba otra de las importancias de El día más violento, reconstruir la vida y obra de Carmen Serdán es relevante porque arroja nuevas luces sobre mujeres trascendentales dentro de la revuelta armada, recuerdos que habían permanecido enterrados o abandonados. Por ello, la obra contribuye a evitar el ostracismo con que la heroína ha sido tratada: "La biografía de Carmen Serdán es singular porque se encuentra repleta de discrepancias y misterio. Hay tantos huecos significativos en su vida que solamente una ficción 
histórica documental de calidad podría llenarlos con éxito" (Martínez, 2010, p. 47). Y por eso, cobra significación El día más violento, pues llena vacíos y cubre posibles dudas, pero sobre todo aclara una cosa, la historia de Carmen es tan importante o quizá más que la de su hermano. Esta es una bala perdida que arroja la dramaturga. ¿Es pecado morir joven?, ¿sólo los hombres se ganaron su eternidad en el Olimpo revolucionario? La obra despeja esas y otras variantes al someter al juicio crítico de la actualidad los eventos revolucionarios:

Arquitecto: Ha sido un verdadero placer conocer a una heroína.

Carmen vieja: Los héroes se mueren. Jóvenes.

Arquitecto: ...Supongo...

Arquitecto: Pues, para la historia. Usted lo sabe muy bien, este país ha pasado por demasiado y necesitamos cosas, visibles, enormes, para recordarlas.

Carmen Vieja: Su nombre está escrito en una placa de bronce, arquitecto, la vi acá. Fue sólo por eso $[\ldots]$

Aquiles: Vaya, qué manía la tuya de vivir. ¿Y qué pasó?

Carmen Vieja: ¿De qué?

Aquiles: Con la Revolución.

Carmen Vieja: En construcción, hermano. Con andamios. Todavía (Colio, 2011, p. 33, 78).

Esta parte es la posición más insistente en la obra, pues se somete al juicio del tiempo los logros de la gesta revolucionaria. La autora utiliza la estrategia teatral de los andamios, parte hoy vital del teatro y sin los cuales prácticamente no habría escenario. La metáfora del andamiaje funciona perfectamente para entender qué parte se dejó en construcción dentro del gran escenario que proyectó la revuelta comenzada en 1910, como es el caso de la desigualdad económica o la discriminación, temas mencionados en la obra: "a la estructura dramática de El día más violento decidí llamarle andamiaje. Porque sucede en un país como el nuestro, en eterna construcción" (p. 97).

La pieza de Colio recrea varios pasajes de la vida de Carmen Serdán, incluyendo sus primeras actividades bélicas, como la fabricación de bombas caseras: 
Voz de Mamá: No andarás jugando con fuego. ¿Verdad, Carmencita?

Carmen Joven: No mamá. Te estoy haciendo unos dulces.

Voz de Mamá: Ay hija, no puedes negar la cruz de tu parroquia.

Cocinando como la buena señorita poblana que eres.

Carmen Joven: Lo soy. (Termina su bomba, la contempla)

Voz de Mamá: Casi es hora de irnos a misa. No tardes. (Se aleja)

Carmen Joven: (Santigua su creación) Amén.

(Murmura) Viva la Revolución (p. 27).

Asimismo, la pieza recrea la dualidad entre religiosa y rebelde de la guerrera mexicana, por un lado, era fiel creyente y, por otro, tenía ideales firmes sobre el naciente movimiento revolucionario:

En una época casi imposible para una dama de clase media, Carmen y otras mujeres formaban parte del club poblano anti-reeleccionista "Luz y Progreso", tiempo antes de empezar la Revolución. Todas ellas acumulaban armas y fabricaban bombas, practicaban espionaje, y conducían reuniones secretas hasta dentro de la iglesia, también usaban diferentes seudónimos, el de Carmen era uno masculino: “Marcos Serrato" (Martínez, 2010, p. 48).

Estos apuntes dan fe de la voluntad guerrera del personaje, lo reivindican y lo muestran ante nuestros ojos como una mujer compleja, de altos valores religiosos, como hija de familia, como excelente hermana y con una conciencia ideológica tan importante o más que sus hermanos. Sin embargo, para Martínez-Ortiz el empeño de la crítica histórica masculina por querer resaltar los mitos de las soldaderas, por ejemplo, la Adelita o la Valentina, han obnubilado la imagen de Carmen y otras mujeres, a las cuales se le ha condenado al olvido.

Carmen no solamente se anticipa, sino que se entrega a la causa. No murió, pero pudo haber muerto. Paradójicamente, a pesar de haber sido la más expuesta, en los balcones, la azotea, los patios, los corredores y la puerta abierta a Cabrera, no murió y apenas si fue herida... Pero... aceptemos que Carmen estuvo a dos pasos de la muerte y que el que no haya 
caído no demerita un ápice su generosa entrega (Mendieta Alatorre, 1971, citado por Martínez, 2010, p. 52).

No obstante, en El día más violento la propia protagonista se muestra frustrada con su destino. Su vida dio un vuelco después de los eventos del 18 de noviembre, pero estos eventos la dejaron sola, sin un aparente objetivo o directriz en su camino. Así lo comenta Carmen Vieja, cuando recuerda las pláticas con su hermano:

Carmen Vieja: Escucharte hablar así me alimentaba más que cualquier cosa, Aquiles. Sentía que mi corazón latía como bomba, y que no había nada más importante en el mundo que defender tus ideas con mi vida. Lo hice. Lo hice. Y lo volvería a hacer [...] Carmen Vieja: Quería un país libre, el que tú me contabas, lo quería con rabia (Colio, 2011 , p. 40, 42).

En el tiempo actual de la obra, Carmen se ha convertido en una vieja, aún conserva su agudeza crítica, pero ha perdido la fe en los movimientos sociales. Piensa que su tiempo se acabó o debió acabarse cuando mataron a su hermano, cuando a ella le negaron la gloria de defender sus ideales, cuando la suerte decidió dejarla viva. Sin embargo, recuerda su juventud y su empeño en la causa, aún después de la muerte de sus hermanos. Por ejemplo, cuando rememora su estancia como enfermera. Aquí, la pieza se vuelve bastante experimental y alegórica, Carmen observa al enfermo moribundo, que es México, y el cual corre peligro en manos de un mal doctor, interpretado por Huerta. En otra escena, el herido (el pueblo de México) muere sin saber que sus hijos, en un futuro, preferirán irse del país a probar suerte con otro idioma y otra cultura, y verán la Revolución en un documental, sin conocer su pasado ni su historia.

En la siguiente escena, Carmen acude a ver a Zapata por petición de Carranza para entregarle una carta donde le pide deponer las armas. Este no la recibe, al final los carrancistas y los zapatistas se matan entre ellos. Todo ha sido como un sueño, nuevamente Carmen Vieja recuerda todo como su pasado. Aunque la perspectiva de Colio es una teatralidad de tipo posmoderno con 
toques surrealistas, la escritora se aventura a mencionar los pasajes poco difundidos y comprobados de la guerrera mexicana, como el caso de su paso por la asistencia de enfermos o la incursión como mensajera hacia las huestes zapatistas. A pesar de no ser una obra, enteramente histórica, El día más violento recupera pasajes prácticamente olvidados o nulos en la historiografía sobre Carmen. Otra cosa que hace Colio con su interpretación es reivindicar y dignificar la historia sobre la poblana ilustre, esto a diferencia de alguna parte de la historia oficial, la cual ha preferido quedarse sólo en los eventos del 18 de noviembre. Además, como menciona Martínez-Ortiz: "La poderosa presencia de la poblana heroica sobrepasa el arquetipo cultural dominante al problematizar y cuestionar la simplista, pero común representación tradicional de la mujer en el campo de batalla." (p. 54). Esto es otra de las lecturas que requiere la historia de Carmen Serdán, la visión de género², que bien muestra Bárbara Colio, no sólo en la configuración de sus personajes, sino en la mentalidad de la protagonista:

Arquitecto: Vea, su altura es mayor que la de cualquier edificación semejante en Latinoamérica y-

Carmen Vieja: Nunca he entendido esa obsesión de los hombres.

Arquitecto: ¿Cuál?

Carmen Vieja: Decir que lo suyo siempre es lo más grande (Colio, 2011, p. 28).

La obra de Colio alimenta el interés por rescatar estas figuras, hasta hoy un tanto difusas de la Revolución mexicana. Mediante la ficción dramática se estimula el interés por estas mujeres, asunto que a diferencia de los caudillos masculinos (Villa o Zapata), no se ha analizado con profundo interés. Como en el caso de Felipe Ángeles, la obra de Colio concluye con un cierto halo de amargura sobre los resultados de la Revolución y sus efectos sobre sus héroes. Así lo menciona la propia autora de El día más violento:

La Revolución resultó ser precisamente una serie de grandes pasos dados; demasiados hacia atrás y otros tristemente perdidos: como el paso a un real reparto de tierras, el paso a

\footnotetext{
2 Por no ser uno de los objetivos primarios de este trabajo, este tema no será explotado aquí.
} 
la no discriminación, el paso a que cada uno de los mexicanos cuenten con seguridad social, educación, un techo, trabajo (p. 97).

Es evidente que la marginación que sufrieron estos personajes es distinta, el primero, Felipe Ángeles, se debió más a cuestiones políticas y a Carmen Serdán fue más por razones de discriminación de género, asunto que afortunadamente hoy ha ido cambiando y se le ha reconocido a Serdán como la autora del primer disparo, con el cual dio inicio la gesta revolucionaria de 1910.

En estas obras opera un destino funesto, el de Ángeles es la tragedia clásica, el destino del héroe, el sacrificio que llega como bálsamo ante la muerte inminente. En este diálogo se cuela la amargura del general ante el resultado adverso de los eventos revolucionarios. Para el sentenciado, la derrota que implica su asesinato es cosa menor en comparación con el fracaso de la revuelta. Asunto que, una vez más, confirma el deseo de anteponer la vida, antes que los ideales. Así lo mostró el estoicismo del general Ángeles:

Ángeles: No se pierde. Yo no jugué para perder, ni para ganar. Yo luché por unos principios. Lo que usted llama triunfo, para mí es una derrota. Mi muerte es una derrota más de la Revolución, una derrota de ustedes los que me matan... (Garro, 2016, p. 234).

En el caso de Carmen, da la apariencia que le robaron su destino, ella también ansiaba el sacrificio, la muerte joven, el premio para los guerreros que dan su vida para tener un porvenir mejor. Sin embargo, esto no sucedió así, y esto vuelve a su historia todavía más trágica, pues se le niega la virtud de la eternidad.

Carmen Joven: Dijiste que hasta el final.

Carmen Vieja: ¡Ese día! ¡Yo quería morir es día en combate! Te lo pedí, imaldito seas!

Aquiles: Voy a esconderme en el sótano.

Carmen Vieja: Y me dejaste sola.

Carmen Joven: No. Prométeme que nos volveremos a ver.

Aquiles (Le da un beso en la frente) A ti no te harán daño...

Carmen Vieja: Sí lo hicieron. Me dejaron viva (Colio, p. 44). 
La memoria histórica es uno de los asuntos principales de estas obras, pues uno de los intereses de Garro y Colio es construir una memoria que dignifique y recupere a personajes ilustres poco conocidos, sin estigmatizarlos ni menospreciarlos como ha ocurrido con Carmen Serdán y Felipe Ángeles. La visión de una historia selectiva y poco honesta es una de las premisas principales que comparten ambas dramaturgas y, aunque pueda sonar anacrónico, la intención es construir una historia que otorgue su lugar a cada uno, sin tener que ser pasado por el filtro de la conveniencia política o de estructuras patriarcales que menoscaben los méritos de heroínas ilustres.

Y por ello cobra relevancia comparar el teatro histórico que se ha hecho en México, porque coloca en el escenario a los héroes muertos, los resucita y les otorga un valor, a veces diferente al que les había dado la historia oficial. Este tipo de representación nos devuelve la esperanza de que la historia justa es real, al menos es escena. En la historia de Elena Garro, el general Ángeles trasciende y sobrevive a la injusticia a través de morir con sus ideales intactos. En la obra de Bárbara Colio, Carmen Serdán vuelve a combatir a los federales, pero esta vez muere junto a Aquiles, se van juntos como, quizá, se lo prometieron alguna vez.

¿Cuál es la alusión que portan estas obras? ¿Cómo se emparentan a pesar de estar escritas con tantos años de diferencia? Felipe Ángeles y El día más violento son dos piezas que recuperan un pasado oscuro, con personajes sombríos y desafiantes para el poder, ya sea el político o el patriarcal, que al final pudiera ser el mismo. La visión femenina de Garro y Colio permite que podamos conocer las facetas desconocidas de los personajes y que podamos entender un perfil más humano y honesto de los actores de la historia mexicana. Elena Garro, con su obra, le da a Felipe Ángeles la notoriedad que le arrebató la situación política de aquellos entonces, pero también le brinda un aspecto más humano, más real, pues como se ha dicho a lo largo de este trabajo, la autora elimina de sus personajes la masculinidad imperante y prototípica que se solía proyectar en los hombres revolucionarios. Garro, con este planteamiento desmitificador de la hombría recalcitrante de la época, se adelanta a su tiempo y nos brinda un general de carne y hueso que llora ante la adversidad y la injusticia. Así mismo, Bárbara Colio critica el mito de la participación 
secundaria de la mujer en la Revolución con su visión valiente y entregada de Carmen Serdán. En su historia, Carmen es la líder, la protagonista que se subleva contra la imagen que nos dieron de ella en los libros de historia. La versión de Colio es la reconstrucción ficticia del destino posible que pudo haber tenido la heroína poblana, pero también es la perspectiva femenina en que se puede contar la historia, donde no se les niegue importancia a las mujeres y se les otorgue el justo valor que merecen. Por ello, ambas obras, aunque se hayan escrito con tanto tiempo entre ellas, se encuentran unidas por una misión de contar la historia no dicha, la que a veces no se quiere escuchar.

\section{Referencias}

Colio, B (2011). El día más violento. México, Jus: Compañía Nacional de Teatro.

Flores, R. (2001). A la mujer (De Regeneración, septiembre 24 de 1910). En: La Revolución mexicana. México: Editores Mexicanos Unidos.

Galván, D. (1987). Felipe Ángeles de Elena Garro: sacrificio heroico. Latin American Theatre Review, 20(2), 30-33.

Garro, E. (2016). Felipe Ángeles. En J. Garro y G. Schmidhuber (Pról.), Álvaro Álvarez Delgado (Ed.), Teatro completo (pp. 177-244). México: FCE.

Maestro, J. G. (2004). Cervantes y Shakespeare: El nacimiento de la literatura metateatral. Bulletin of Hispanic Studies, 81(4-5), 599-612. https://es.scribd.com/doc/86312840/Cervantes-yShakespeare-El-Nacimiento-de-La-Literatura-Metateatral

Martínez-Ortiz, M. T. (2010). Carmen Serdán: la invisibilidad histórica de las guerreras de la Revolución Mexicana frente a las representaciones culturales del mito de la soldadera. Graffylia. Revista de la facultad de filosofía y letras, 7(11-12), 44-57.

Prado, G. (2006). Avatares revolucionarios: Elena Garro y su re: cuento de la historia. En L. E. Gutiérrez de Velasco y G. Prado (Eds.), Elena Garro. Recuerdo y porvenir de una escritura (pp. 87-104). Toluca, México: Tecnológico de Monterrey, campus Toluca/ Universidad Iberoamericana, Ciudad de México/ Fondo Nacional para la Cultura y las Artes. 
Olguín, D. (2011). Un teatro sólido: Elena Garro. En C. Gidi y J. Bixler (Coords.), Las mujeres y la dramaturgia mexicana del siglo XX. México, Ediciones El Milagro/Universidad Veracruzana/Universidad de Sonora/Universidad de Virginia Tech.

Osorio, R. (2008). General Felipe Ángeles: Consejo de guerra y fusilamiento. En A. Gilly (Comp.), Felipe Ángeles en la Revolución. México: Era/Consejo Nacional para la Cultura y las Artes.

Rivera, N. (28 de noviembre de 2019). Felipe Ángeles, de Elena Garro, reinaugura el Teatro Reforma. [Versión electrónica]. Proceso. https://www.proceso.com.mx/cultura/2019/11/28/felipeangeles-de-elena-garro-reinaugura-el-teatro-reforma-234986.html

Seydel, U. (2010). Felipe Ángeles: la reivindicación de la soberanía del Yo. Literatura Mexicana, 21(2), 75-90.

Seydel, U. (2006). La escenificación del poder en Felipe Ángeles. En L. E. Gutiérrez de Velasco y G. Prado (Eds.), Elena Garro. Recuerdo y porvenir de una escritura. Toluca, México: Tecnológico de Monterrey, campus Toluca/ Universidad Iberoamericana, Ciudad de México/ Fondo Nacional para la Cultura y las Artes. 